\title{
An Experience of Applied Conflictology
}

\author{
Boris I. Khasan* \\ Siberian Federal University \\ 79 Svobodny, Krasnoyarsk, 660041, Russia
}

Received 09.07.2015, received in revised form 11.09.2015, accepted 25.09.2015

The article considers the phenomenon of the conflict as not only natural and destructive phenomenon. Conflict is understood as a form of contradiction to be held in its resolution. The possibility of special designing and constructing of artificial conflicts to solve the problems of individuals and groups is discussed. The possibility of forming the cultural tradition, where specially designed conflict can become a form and content of education, is stated.

Keywords: conflict, constructive psychology, conflictophobia, psychotechnics, development, education.

The study was financially supported by the Russian Foundation for Humanities (RFH) project research "Methodological approaches to the monitoring of migration flows for the formation of a management system of quality of life of the population of Siberia and the development of differentiated territorial policy of the country» supporting by Krasnoyarsk regional fund for supporting scientific research and technical research activities, project № 15-12-24008.

DOI: 10.17516/1997-1370-2015-8-11-2789-2797.

Research area: psychology.

\section{Part l}

\section{Constructive Psychology.}

\section{Anthropotechniques Conflict}

Connecting in the discussion two provisional terms, not yet grounded by any solid concept restained in the professional culture may seem strange, provocating, pretending to be epatant. Nevertheless, I undertake such an attempt, assuming that the content already exists, but it is to be arranged by the presently forming interprofessional community, that is partly realized in the present paper.

By "constructive psychology" I mean a domain of theory and practice which deals with construction of new artificial mental phenomena (Golovakha E. I., Kronik A. A., 1987). However, it likewise concerns natural mental phenomena like natural abilities and behaviour artificially displaced from the mind of an individual.

First of all, it concerns dialogue or, more exactly, dialectic way of thinking (or way of life in a broader sense). Now it needs restoring and even constructing anew. Moreover, the very constructing should be singled out as a specific psychotechniques which, in its turn, requires a new culture.

Hence, we may preliminarly define the anthropotechniques as a special complex

(C) Siberian Federal University. All rights reserved

* Corresponding author E-mail address: khbi@ippd.ru 
artificial work providing humanization and aiming at developing vital activity and thinking ability of people, i. e. not only individual and sociopsychological but also cultural movements (technological, economical and political) which set ways of thinking and activity.

The transition from constructive psychological to anthropotechnical approach is related to much wider meaning of creative work with the very psychological inside of it, both as an aspect of influence and as a professional means alongside with others.

Now, meaning the anthropotehcnical orientation, genetic roots and actual living conditions of an individual, one can single out one of the most important contradictions whic need solving within the framework of the constructive psychology. This is, on the one hand, individualsusceptibility to influence and longing for this influence, andon the other hand, striving for independence and self-mastering. In other words, a dialectical dilemma of dependence/ independence.

This dramatic contradiction should be naturally resolved through a conflict. But helas...

Attempts to get rid' of a conflict by every means are recognized as senseless long ago, however, we have to admit that these attempts are anyhow "useful" since taking the conflict as something natural and mainly negative, psychologists invented artificial ways of fighting it. Howver, "together with water one tipped a child out". The conflict is still not overcome, but human activity, first of all, education, i. e. moulding of mentality and culturally regulated behavior was deprived of dialectic character and of ability to active experience (Vasilyuk, 1981). Thus, thefight against invalid experience ofa conflict still led to invalidity, though to a different one. The fight itself resolved some instantaneousproblems but unfortunately, did not transcend the limits of psychological objectivity. That's why nowadays, in terms of theanthropotechniques, both the ways of fighting and the very objectives of the fight look invalid.

The current psychotechnical objective consists in constructing again naturally given but never assimilated and destroyed psychological mechanisms.

Now we need such modes of human compatibility and co-existance that would contain a developing mechanism: solution of a conflict adequately experienced emotionally as an act (step) of development.

Let us take up resolution of the contradiction between striving for dependence and independence. The actual process of assimilating the culture and socialization can be considered as the strengthening dependence of an individual on surroundings, on other people, on his own needs etc. At the same time awareness of the dependence and recognition of limited potentials of the self can and should clear up the very transcending of the limits. Or, the very fact of discovering the limit potentially instigates "dislimiting".

Note that the solution here acts as a peculiar paradoxal "unity" where one action colliding with another becomes a means for its realization and vice versa.

Taking into account how easily we associate this situation to the dialectical law of unity and fight of opposites I note, that with any actualhuman "matter" the incarnation of this entity would require quite uncommon psychotechnical constructing of all the logics of acting.

Why are well-known and successfully tested means useless?

The common psychotechniques dealt with natural mental phenomena and aimed at "technical" or artificial facilitating their most effective disclosing or elimination (Munsterberg, 1925). 
Inspite of the fact that russianpsychologists for a long time pretended that psychotechniques does not exist, the latter made serious steps forward hiding behinddifferent names such as psychological correction, theurapy, moulding experiment, training, which can be qualified only as perfecting of the already discovered. Recently the re-discovery and revising of theoretical and methodological foundations of psychotechnical heritage became typical of the home psychology (Pusyrey, 1986). Evidently, it is high time to move ahead in this domain.

The analysis of a large number of reports on the psychotechnical practice shows that psychologists people address to deal mainly with conflicts. The psychologists dispose of various means to resolve conflicts, from common psychoanalysis till the most advanced training and direct theurapy.

Unlike the common psychotechniques (as, for instance, psychodrama), the constructed conflict is developing on realities of the problematic activity and not in a compensating therapy (game).

Its matter and consequence is not a past action but the present and the future onethat need an actual emotional experience and growth of a new ability.

Main shortcomings of traditional approaches stem from the fact that division into instances bearing a contraduction and those of a conflict action unambiguously led to understanding the solution in favour of one of conflicting instances or in favour of a third instance. A funny situation emerged: a psychotechnician joining himself with one of the instances never worked for the sake ofan individual posessing some potentials but for the sake of the instance in the latter which needed help at the moment.

If we mean the work for a man in prospect, we should construct just the mechanisms he doesn't need at the moment. Here is another situation fraught with conflicts where a psychotechnician and a "patient" act as the oppositesides, and their cooperation and conditions of its realization are considered as an object. Besides, one should single out here both actually professional problems of the constructive psychotechnical aspect, and anthropotechnical ones, including projection and construction of those vital conditions which would provide both a balanced functioning of new mental phenomena and the mechanism of its development.

Thus, mastering a conflict in the constructive psychology differs greatly from the fight against it in the common psychology. The anthropotechnical context sets a much wider methodological and practical approach and requires objective and not subjective consideration and thusleads to a new cultural leve I.

\section{Part 2}

\section{Nature and Mechanism \\ of Conflictophobia}

Examining a conflict in terms of functional approach (destructive or constructive), i.e. assuming it as a provisionally natural phenomenon of human life and activity, requires a a complex attitude both in theory and practice. Such an approach always encountered, and still does, a significant opposition among psychologists. The constructed conflicts is the more so strange in the applied psychology as it pretends to bea psychotechnical means, artificially createdfor resolving contradictions.

To a considerable extent such situation is due to lasting attempts to study conflicts in terms of mere psychology, though anybody who is seriously involved in this problem realizes that one cannot do without cooperative job of dialectical logics, ethics and contextual study of the activity generating the conflict.

What does hinder such a cooperation? 
The main contradiction to be solved, when placing a conflict in the context of social practice, individual psychology and scientific suject consists in rather clear understanding of functions of a conflict as a mechanism for resolving contradictions through actions and providing the development of a human being and a society accompanied by evident and stable fear for a conflict as a fact of human existence.

Both sociological and psychological studies show that no persuasions or scientific accounts for inevitability or even usefulness of a conflict can reduce and remove the fear of conflicts, both as social phenomena and facts of individual emotional experience (Terner, 1985; Vasilyuk, 1984).

The undertaken efforts to separatethe conceptsof contentful (good) and communal (bad) conflicts are evidently not effective, because the matter is not only in hermeneutic success or failure, but in the existing cultural tradition which is translated somehow by transmission of norms through education, art science, religion and is at the same time grounded by a psychological life of indivuduals.

The conslusion seems to be straightforward: it is necessary to set up and consistently cultivate a new cultural tradition, mainly through education. But this requires exposing the successfully working reasons and psychological mechanisms of the conflictophobia in order to create conditions for introducing conflicts as form and content of education.

It looks no less important in terms of therapy which usually tries to escape from conflicts just because its resolution requires constructing, and for a patient it means to be involved into another conflict.

The most important item in the psychological discussion of conflicts is that any conflict irrespective of its matter and phenomenal realization (inner or outer) is formed as a structure by splitting of the self (ego), and as a process by mutual changes in the collided actions (action modes).

Insisting on the fact that this thesis is related both to inner and outer conflict, I would note that the essensial difference between inter-facing where the activities change mutually and facing where only one activity is subject to changes. The investigations of introspective fixations in some cases show that there are at least two types of interpretation of an incident (regardless of behavioral, gestalt or cognitive orientations) which reason further development of actions either as a conflict or as overcoming an obstacle (I specially stress it once more as different). The latter is commonly realized as frustration with all possible consequences, including a conflict (Vasilyuk, 1984). But this is deeper inside. The former is interesting by the immediate realization of splitting of the self into bearers of different modes of action.

Thus, I assert that the reciprocal interiorizing of the opposing sides (cohesion) starting from the moment of collision (in terms of inter-actions) up to the resolution of the conflict implying autonomization of an action with a new or retained quality and restoring of integrity of the self is a necessary attribute of any conflict and, moreover, its essential feature as a specific psychological phenomenon.

Variability of modes of actions immediately gives rise to a painful difficulty in choice.

Since only one action can be fulfilled at once the choice must be unequivocal.

The content of the actions of choice displays the essence of the conflict. Its main problems in a psychological aspect are that "self"-splitting produces several instances at once whiich cannot actualize as they are.

Co-existence of instances of the splitted self is possible, to my mind, in two cases: either as 
actless, or acting in different time or space. The latter always generalizes only one instance.

I am aware that such an approach is simplified and I leave the question open to some multi-level consideration, as is commonly done in the psychology of conflict. I must worth stressing that the necessity to find an unequivocal solution (a simplified or linear model) rules out the ranges in strategics of behaviour in a conflict proposed, for example, by M. Deutsch and K.Thomas. Such a range can be realized only in an outer interaction of quite different bearers with their own ontogeneses. In our case all the instances are selves but having different modes of actions.

To overcome the splitting (or to resolve the conflict) and to restore the integrity of the self by a choice means a refusal that is the most difficult (and hence painful) emotional experience. But the refusal of one of the modes of actions means at the same time the necessity to discredit an instance-bearer which is the same self!

Here I should stress a components of the conflictophobia mechanism formulated as follows: "a conflict is a choice; a choice is always a refusal; to refuse of oneself, even partially, is painful and terrible".

Nevertheless this mechanism is inevitably based on a necessary inevitable conflict in everyday consciousness as a desire to escape from or to get rid of what can't be escaped. Personal emotional experience like that forms in an individual the respective phobic attitudes.

According to Freud the choice is realized due to a hierarchyin the structure of the self and different organization of instances. Discrediting an instance in the psychoanalysis means displacement. But all the researchers and practicians of psychoanalysis know what the displacement is fraught with.

It means that the actual resolution of the conflict, and not dragging it out and sublimation, in terms of the simplified approach requires either to accept "elimination" of one or several instances, whose modes of actions are not realized, that provides uniqueness and stability of the choice, or to resign oneself to a constant threat of splitting that means revival of the conflict.

Here resides the second component of the conflictophobia: "the conflicting part of the self cannot be eliminated because it is almost a suicide, that is why in the case of a once-takenplace conflict ego is doomed to remain under the threat of its unpredicted actualization". This component is characteristic for a deeper existential level and presents a more solid ground for the conflictophobia.

If the proposed speculations are admissible ${ }^{1}$ the conflictophobia can be overcome in two ways.

First, to crearte a culture of "elimination" (how strange and awfully it might sound) of the instance, whose action can't be realized as a resolving/resulting collision. Dependent on the content of the contradictions involved in the conflict, we need developing a range of the respective psychotechniques providing the "elimination". Here we should specify the content of the conflict, since moral collisions may requiretheir specific"tabu" on "elimination".

Ther respective experiments have shown, that the idea of "elimination" of instances is not so fantastic as it would seem at the first sight.

Second, to train (to cultivate) the culture of conflict where reasons of both instances (in more complex cases of more instances) can be used as a constructive matirial for growing a new action (activity), AS a matter of fact, we mean formation of a potential super-instance, where the integrate reflexing self is retained inspite of any splitting.

I feel that this is the only way to practice the non-simplified approach to a conflict and to actually resolve the contraduction it stands for, unlike the conflict of choice commonly discussed in psychology. 
The word "train" ("cultivate") is specially charged meaning specific psychological and pedagogical work on early stages of ontogenesis. It is at these stages, at the begining of the development of game activity, followed by the educational one, that a child has no yet conflict stereotypes, no phobias of self-splitting that saves him from a рге-conflict phobic emotional experience, appearing in an adult whois aware of conflict-bearing nature of a situation.

\section{Part 3}

\section{A Pithy Conflict as a Prerequisite of Educational}

Activity and a Mechanism for its Development

An educational/cognitive task is the focus and the core of the theory of educational activity and of the whole concept of developing education (Davydov, 1986). Constructing, resolving and discussing it is the principle concern of educators and psychologists.

However, psychologists have not yet resolved a problem of activity which would serve as a context for the educational/cognitive tasks an individual faces. If one develops this question in terms of psychotechnics it will look as «How and where a pupil gets puzzled (gets his task)?»

Before discussing this problem we have to outline the subject of study. This is generally teacher's activity embracing pupil' $s$ activities .

The educational activity itself is, on the one hand, an objective of pedagogical activity and on the other hand it is its subject.

The discussion of educational activity as a teacher's objective is connected with its artificial origin and organization. Psychological reasons of cognition and education lie already in the play activity and take shape as though by natural way(?) at subsequent age stages. At the same time a transition to such educational matter, which has no direct empirical presentation, is absolutely artificial any time, demanding special technique.

The study of learning practice show that its subjects are of two extreme types: those instructed and those learning. Those of the first type are «pure» objects of instruction indifferent to the content of education. The manipulations related to the educational course are for them no more than stipuulations for solution of some another task beyond the educational-cognitive development.

Those of thesecond type, initiated under a certain situation, appropriate the educationalcognitive objectives, turning the educational content into the subject of their own activity.

The posed question about puzzling pupils is evidently related to those of the second type. For those of the first one the question would never arise. And this is a common practice of the whole school of our time, from theprimary to higher one.

Drowing a pupil into educational process is always connected with these or those formalities, making the illusion of interest, of an extraordinary situation, giving a momentary but a markedly fixed result. In order not to sink into a critical passion I note only some actual pedagogical orientations, in opposition to which the applied psychology is practiced in the Krasnoyarsk university:

1. Pedagogical experiments or trials with formal organization at invariable educational matter.

2. Aiming at assimilation of certain domains of knowledge beyond a general content of activity (a non-subject approach).

3. An apriori assumption that only goood memory and speech provide good mental development.

The task of drawing into educational activity in a primary school, is actually solved by D. V. B. Elkonin, V. V. Davydov, V. V. Repkin, 
L. I. Aidarova, V. V. Rubtsov, O. A. Tsukerman, Yu. A. Polyanov, S. Yu. Kurganov etc at the expence of natural and mild transition from a playgame to education. Evidently, till a certain moment (the definition of this period and a moment of transition needs special investigations), educational activity of junior pupils should take place inside a playgame as a corresponding form and even serve the game.

The pupils of senior age must require a different approach. In this case we may use conversion: the game activity here is a means of education and not vice versa. But it is necessary that a pupil, first, were already involved in resolving the task posed from outside and unsolvable by the known means and, second, could treat his own situation as playing, and in this way to widen a range of the task, putting the «alien» imposed task into a more general «own» one; third, he should get aware, by reflexion, of the contradictory character of the situation where the impossibility to resolve thealien task opposes his own needs.

Thus, subjectivation of an instructive/ cognitive problem and, consequently, fulfillment of an instructive action are possible through resolution of an inner conflict of a pupil rooted in the necessity of choice between a pithy progress enhancing his self-apprecition and showing him a new side of himself (his abilities) and of the world, on the one hand, and, on the other hand, a refusal of defending his former self-appraisal. The subjectivizing itself means transition from the state of being instructed into that of active learning.

The instructive action not to turn into a single fragmental act requires that a pupil reflexively «grasped» the whole mechanism of the subjectivation and then converted it into a mode of action and a new ability.

Schematically, in an instructive play it looks as follows.
According to game terms groups of instructed players receive a collective task, known to anticipate their actual abilities and lying within the zone of the nearest development. The organizers proceed from the fact that the means necessary for to solve such tasks are making up a subject for the future study. The atmosphere of game and non-personified actions free the pupils from responsibility and allow to propose solutions at random.

In the discussig it turned out that first, the task was «solved» because itwas «given», due to a stereotype of disciplined behaviour in the system of relations «teacher/pupil», i. e. solved not for oneself but for the teacher; second, a pdychological situation in every group of players, as a rule, is so that except an imposed task one more is actually being solved, the one's own, connected with the status of a group and selfappreciation; third, similar attitude to the imposed task (a stereotype of a formal execution) turns not to raise but, on the contrary, to lower the status and self-appreciation.

Here, the instructor either can act as a side in an outer conflict or as an organizer of inter-group collisions (this is more effective), not missing primitive actions of the groups. At the expence of fixation in the discussion the third conclusion, collision is translated into an inner conflict.

The inner conflict becomes a subject of the further discussion, it can be solved either by a new attitude towards the set taskproviding it with a new value, or by defence and going out of the play. The participants are aware of both issues. That is why every time the solution has a perfectly pronounced personal shade.

The first issue impllies a question of what means are necessary for resolving the problem. Actually, the solution, or a way out of the deadlock, is being outlined.

Reflexion of the work doneallows a participant to separate the "imposed" and "own" 
problems, to interrelate them and to single out a way of theconflict as a main mechanism of efficient progress and self-development.

Thus, the experiment provides us with a stimulating join of teacher's and pupil's activities, a kind ofintersection of their situations.

Construction and organization of the pithy conflict in instructive games where a pupil is self-developing in his own cognitive process is a difficult psychotechnical problem of a teacher.

Such an approach to pedagogical organization, provision and development of instructive activity puts forward quite different from the common requirements to the subject of learning.It becomes no longer indifferent to the forms of instruction, inasmuch as it always means to pupil a tool and an intermediate goal in a complex system of activity and personal formation.

Evidently, this approach contains a possibility to resolve one more problem which is of extraordinary importance but still open. Learning actually supposes a relative independence of a pupil, as far as an instructed is transformed into a leaning his activity should free itself from tight "embrace" of pedagogical activity. Such autonomization can be provided only through the solution of a conflict by mastering reflexive abilities, the respective techniques, ways and means of learning itself.

Our investigations based on the solution of conflict-generating problems (see [4]) provide a solid proof for presence of the first component; the presence of both components of the conflictophobia mechanism was shown by a relatively small number of the people under test.

\section{References}

Conflicts as psychotechnical means. Independency personality and group. Riga, 1989. p. 183.

Khasan, B. I. Conflict and its resolving In: Problems of Juniors Selfdetermination. Krasnoyarsk, 1987. p. 20.

Khasan, B. I. Exteriorisation of internal conflict In: Intellectual systems \&imitation. Novosibirsk, 1985. $188 \mathrm{p}$.

Terner G. The Structure of sociological theory. Moscow , Progress, 1985. 470 p.

Vasilyuk Ph. E. Psychology of Experience. M. , Moscow University Press, 1984 199pp. 


\section{Опыт прикладной конфликтологии}

Б.И. Хасан

Сибирский федеральный университет Россия, 660041, Красноярск, пр. Свободный, 79

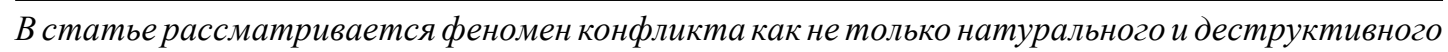
явления. Конфликт понимается как форма, в которой удерживается противоречие в процессе его разрешения. Обсуждается возможность специиального искусственного проектирования и конструирования конфликтов для решения задач развития личности и группьы. Указывается возможность оформления культурной традиции, в которой специиально конструированный конфликт может становиться формой и содержанием образования.

Ключевые слова: конфликт, конструктивная психология, конфликтофобия, психотехники, развитие, образование.

Исследование выполнено при финансовой поддержке РГНФ проекта проведения научных исследований «Методические подходы $\kappa$ мониторингу миграционных потоков для формирования системы управления качеством жизни населения регионов Сибири и развития дифференцированной территориальной политики страны»), проект №15-12-24008.

Научная спеииальность: 19.00.00 - психологические науки. 